\title{
Psychopathology and Parental Stress in 3-6-Year-Old Children with Incontinence
}

\author{
Hannah K. Mattheus ${ }^{1}$, Kathrin Kiefer ${ }^{1}$, Rebecca Freund ${ }^{1}$, Justine Hussong ${ }^{1}$, Catharina \\ Wagner ${ }^{1}$, Monika Equit³, Tina In-Albon, Margarete I. Bolten², and Alexander von Gontard ${ }^{5,6}$ \\ Department of Child and Adolescent Psychiatry, Saarland University Hospital, Homburg, Germany \\ Child and Adolescent Psychiatric Clinic, Department of Developmental Psychopathology, University of Basel, Switzerland \\ Division of Clinical Psychology and Psychotherapy, Department of Psychology, Saarland University, Saarbrücken, Germany \\ Clinical Child and Adolescent Psychology and Psychotherapy, University of Koblenz-Landau, Landau, Germany \\ Governor Kremers Centre, Department of Urology, Maastricht University Medical Centre, The Netherlands \\ Psychiatric Services Graubünden (PDGR), Outpatient Services for Child and Adolescent Psychiatry, Chur, Switzerland
}

\begin{abstract}
Summary: Objective: Incontinence and functional gastrointestinal disorders are common in young children and are associated with higher rates of psychological symptoms and mental disorders. This article focuses on the mutual association between incontinence and related toilet refusal syndrome, parental stress, and children's psychopathology especially in young children. Methods: Children's psychological symptoms, mental disorders, and parental stress levels were assessed in 38 parent-child dyads involving children with incontinence and 42 dyads of typically developing (TD) children. Results: Compared to TD children, patients had higher internalizing and externalizing CBCL scores and higher rates of clinically relevant externalizing problems. However, the rates of clinically relevant internalizing problems and mental disorders did not differ. The parents of children with incontinence reported significantly higher stress levels regarding child-related stress factors (PSI-CD) than did parents of TD children. However, there were no clinically relevant parental stress scores on a group level, which remained below the clinical range (T-value $<60$ ). When simultaneously analyzed, children's (comorbid) mental disorders but not incontinence had a major impact on parental stress. Conclusions: Despite moderate stress levels, incontinence symptoms, urinary and fecal incontinence are highly prevalent in young children. However, stress among parents of young children was mainly elicited by any (comorbid) mental disorder.
\end{abstract}

Keywords: urinary incontinence, functional gastrointestinal disorders, parental stress, psychopathology, young children

\section{Psychopathologie und elterlicher Stress bei 3- bis 6-jährigen Kindern mit Ausscheidungsstörungen}

Zusammenfassung: Fragestellung: Ausscheidungsstörungen (AS) wie funktionelle Harn- und Stuhlinkontinenz sind sehr häufige Störungen im Vorschulalter und sind mit einer erhöhten Prävalenz von psychopathologischen Symptomen und psychischen Störungen bei den betroffenen Kindern assoziiert. Innerhalb der vorliegenden Arbeit wird der wechselseitige Zusammenhang von funktioneller Harn- und Stuhlinkontinenz sowie dem damit in Verbindung stehenden Toilettenverweigerungssyndrom auf die kindliche Psychopathologie und das elterliche Stresserleben speziell bei jungen Kindern untersucht. Methode: Psychopathologische Symptome, psychische Störungen und elterliche Stressbelastung wurden in 38 Eltern-Kind-Dyaden bei Kindern mit vorhandener AS und in 42 Dyaden bei Kindern ohne AS untersucht. Ergebnisse: Kinder mit AS wiesen höhere Werte von internalisierendem und externalisierendem Problemverhalten auf und waren häufiger von klinisch relevanter externalisierender Symptomatik betroffen. Nichtsdestotrotz war die Prävalenz psychischer Störungen vergleichbar. Eltern von Kindern mit AS berichteten signifikant höhere kindbezogene Stresslevel. Dennoch zeigte sich auf Gruppenebene kein klinisch bedeutsamer elterlicher Stress und die mittleren Stresslevel lagen unterhalb des Bereichs der klinischen Auffälligkeit (T-Wert < 60). Bei gleichzeitiger Betrachtung des Einflusses von AS und psychischen Störungen zeigten sich letztere als ausschlaggebend für den elterlichen Stress. Schlussfolgerungen: Trotz moderater Stresslevel konnte eine generell hohe Prävalenz von AS Symptomen bei 3-6-Jährigen aufgezeigt werden. Elterlicher Stress war jedoch bedeutsamer mit einer (komorbiden) psychischen Erkrankung assoziiert.

Schlüsselwörter: funktionelle Harninkontinenz, funktionelle gastrointestinale Störungen, elterlicher Stress, Psychopathologie, Kinder im Vorschulalter 


\section{Introduction}

It is well established that urinary incontinence (UI) and functional gastrointestinal disorders (FGID) in children are often accompanied by further psychopathology. Preschool children with incontinence are more frequently affected by psychological symptoms and behavioral disorders than typically developing (TD) children: $16.8-33.3 \%$ are affected by attention-deficit hyperactivity disorder (ADHD), $4.8-25 \%$ by oppositional defiant disorder (ODD), and $14-20 \%$ by anxious-depressive symptoms (Equit, Hill et al., 2014; Niemczyk et al., 2015; von Gontard, Moritz et al., 2011). In young children, constipation is already associated with heightened frequencies of psychopathological and behavioral problems (Kilincaslan et al., 2014), and about $40 \%$ of children with toilet refusal syndrome (TRS) are affected by comorbid mental disorders (Niemczyk et al., 2014).

Besides its high comorbidity, incontinence is one of the most common disorders in children. According to the International Children's Continence Society (ICCS), nocturnal enuresis (NE) and daytime urinary incontinence (DUI) are diagnosed in children from the age of 5 years on with a frequency of wetting at least once per month for a minimum duration of 3 consecutive months after ruling out medical conditions (Austin et al., 2016). In preschoolers aged between 5 to 6 years, NE occurs with a prevalence of 8.5-9.5\% (Equit, Klein et al., 2014; Niemczyk et al., 2015; von Gontard, Moritz et al., 2011), whereas DUI affects $2.7 \%$ (Niemczyk et al., 2015).

The ROME-IV diagnostic criteria of FGID differentiates between nonretentive fecal incontinence (FI) and functional constipation (with or without FI) (Hyams et al., 2016). FI is diagnosed in children over the age of 4 years when soiling is present at least once per month for 3 consecutive months after exclusion of organic causes and exhibits a prevalence of $0.8-1.4 \%$ in preschool children (Equit, Klein et al., 2014); Niemczyk et al., 2015; von Gontard, Moritz et al., 2011). Children with TRS use the toilet for micturition but refuse to use the toilet for defecation and insist on a diaper instead. There is a great etiologic and prognostic overlap to FGID, as up to $60 \%$ of children with TRS are affected by constipation as well (Niemczyk et al., 2014). TRS as a special subtype of elimination disorder affects $22 \%$ of young children aged between 1.5-2.5 years (Taubman, 1997) and $0.7 \%$ of children over the age of 5 years (von Gontard et al., 2015).

Several studies have shown that school children with NE, DUI, and/or FI have a reduced quality of life (Kaugars et al., 2010), and their parents exhibit significantly higher levels of parental stress (De Bruyne et al., 2009; Kaugars et al., 2010; Wolfe-Christensen et al., 2013). Additionally, parents of young children with constipation report a more overprotective or a more stringent parenting style than do parents of continent children (Kilincaslan et al., 2014). Compared to TD children, children with NE perceive the quality of attachment to their caregivers to be more negative (Schober et al., 2004). Children with TRS more likely grow up in families with more younger siblings and are at a higher risk of having parents with deficits in setting limits, which represents important factors for elevated family stress levels (Taubman, 1997). Taken together, there is evidence for increased psychopathology in children with incontinence and associated FGID and also for higher demands on parents. Although these studies provide evidence of robust associations between children's incontinence, FGID, and psychopathology, further investigations focusing on similar associations with parental stress are required, especially in the group of young children.

This study therefore examined the mutual association between UI and FGID (including FI and TRS), psychological symptoms, and parental stress in a sample of young children from 3 to 6 years of age. We hypothesized that children with incontinence have higher rates of psychological symptoms and mental disorders, and that their parents report higher stress compared to parents of TD children. Further, we hypothesized that, within the group of children with incontinence, those affected by FGID express higher rates of psychological symptoms and mental disorders, and that their parents report higher stress compared to children with only UI. Another aim of the study was to analyze possible interaction effects between incontinence, mental disorders, and parental stress.

\section{Methods}

\section{Procedure}

Patients were recruited at a tertiary outpatient clinic for incontinence. The control group of TD children matched according to age and ex, was recruited in kindergartens and sports clubs through newspaper ads. Parents were informed about the study via telephone. Children were included in this study after their parents gave written informed consent. Patients were diagnosed with NE, DUI, or FI according to the ICCS and ROME-IV criteria. TRS was diagnosed according to Christophersen's and Edward's (1992) criteria of symptoms occurring at least for 1 month. The assessment included a voiding diary, a neurological and pediatric examination, ultrasound and uroflowmetry as well as parental questionnaires (Austin et al., 2016; Hyams et al., 2016; von Gontard, 2012). Exclusion criteria were an IQ $\leq 70$ or a chronic organic disease 
leading to incontinence. TD children did not exhibit any elimination disorders, albeit the occurrence of subclinical incontinence symptoms (voiding or soiling frequency below the diagnostic criteria) was not declared as an exclusion criterion. The study was approved by the local Ethics Committee.

\section{Sample}

A total of 39 children were recruited at an outpatient clinic and allocated to the patient group; $44 \mathrm{TD}$ children were recruited from the general population and allocated to the control group. One child from the patient group was excluded from further data analysis having just missed the required age of 5.0 years for a diagnosis of UI. Two TD children who had incontinence symptoms meeting the diagnostic criteria of NE and DUI were also excluded from further statistical analysis; the children and their parents were informed about incontinence and were offered an assessment at the outpatient clinic. Three more children exhibited occasional incontinence symptoms that did not fulfill any diagnostic criteria and were included as TD children in the analyses. This led to a sample sizes of 38 children aged between $3.41-6.99$ years (44.7\% females, mean age of 5.5 years, mean IQ $=110.7$ ) in the patient group and 42 TD children aged between 3.08-6.92 years ( $42.9 \%$ females, mean age of 5.4 years, mean $\mathrm{IQ}=112.7$ ) in the control group. Groups did not differ in terms of age, sex, and intelligence (see Table 1).
Within the incontinence group, 12 (31.6\%) children were diagnosed with DUI, 22 (57.9\%) with NE, 22 (57.9\%) with FI, 4 (10.5\%) with TRS, and 19 (50.0\%) children with functional constipation.

The patient group was subdivided into a UI group, when patients had only NE or DUI (and no FI, constipation, or TRS) and the FGID group, when they had functional constipation, FI, or TRS (regardless of whether NE or DUI were present or not). The UI group consisted of 10, the FGID group of 28 children, 7 of whom also had DUI and 12 NE. Subgroups within the incontinence group did not differ in terms of sex and intelligence, but children with FGID were slightly younger than the children with UI only ( 5.3 vs. 5.9 years of age, $p=.016$ ). Sample characteristics are provided in Table 1 .

\section{Materials}

\section{Questionnaires}

Psychological symptoms were measured by the Child Behavior Checklist (CBCL 11/2-5 or CBCL 6-18), which consists of 99 (or 112, respectively) problem items, internalizing and externalizing symptoms of the child. Items are calculated into three composite scores internalizing, externalizing problems, and a total problem score and are outlined as $T$-values. A $T$-value above a cut-off of $T>63$ $\left(=90^{\text {th }}\right.$ percentile $)$ is considered as clinically relevant (Döpfner et al., 2014).

Table 1. Descriptive sample and subgroup characteristics

\begin{tabular}{|c|c|c|c|c|c|c|c|c|c|c|c|c|c|c|c|c|}
\hline & \multicolumn{3}{|c|}{ TD children } & \multicolumn{13}{|c|}{ Children with incontinence } \\
\hline & & & & \multicolumn{5}{|l|}{ All } & \multicolumn{3}{|l|}{ UI } & \multicolumn{5}{|c|}{ FGID } \\
\hline & $n$ & M & (SD) & $n$ & M & (SD) & $t$ & $p$ & $n$ & M & $(S D)$ & $n$ & M & $(S D)$ & z & $p^{1}$ \\
\hline Age (years) & 42 & 5.5 & 0.8 & 38 & 5.4 & 1.0 & 0.65 & .519 & 10 & 6.0 & 0.5 & 28 & 5.3 & 0.8 & -2.27 & $.023 *$ \\
\hline \multirow[t]{2}{*}{ IQ } & 42 & 112.7 & 14.5 & 37 & 110.7 & 16.1 & -0.57 & .570 & & & & & & & -0.36 & .732 \\
\hline & $n$ & (\%) & & $n$ & (\%) & & $\chi^{2}$ & $p$ & $n$ & (\%) & & $n$ & (\%) & & & $p^{2}$ \\
\hline Females & 18 & $(42.9)$ & & 17 & $(44.7)$ & & 0.03 & .866 & 3 & $(30.0)$ & & 14 & $(50.0)$ & & & .460 \\
\hline NE & 0 & $(0.0)$ & & 22 & $(57.9)$ & & & & 10 & $(100.0)$ & & 12 & $(42.9)$ & & & \\
\hline DUI & 0 & $(0.0)$ & & 12 & 31.6 & & & & 5 & $(50.0)$ & & 7 & $(25.0)$ & & & \\
\hline $\mathrm{Fl}$ & 0 & $(0.0)$ & & 22 & (57.9) & & & & 0 & $(0.0)$ & & 22 & (78.6) & & & \\
\hline \multirow[t]{2}{*}{ TRS } & 0 & $(0.0)$ & & 4 & 10.5 & & & & 0 & $(0.0)$ & & 4 & (14.3) & & & \\
\hline & 0 & (0.0) & & 19 & $(50.0)$ & & & & 0 & $(0.0)$ & & 19 & (67.9) & & & \\
\hline
\end{tabular}

Note: Total $N=80$. Patients were either allocated to the UI subgroup, when they had only NE and/or DUI, or to the FGID group, when they had constipation, FI, or TRS. Because of the small subgroup sample sizes, group comparisons were performed using nonparametric tests ${ }^{1}$ Mann-Whitney $U$-Test or ${ }^{2}$ Fisher's exact test, respectively. * Significant at $p \leq .05 . T D=$ typically developing. 
The Preschool Feelings Checklist (PFC) is a screening instrument specially created to assess depressive symptoms in preschool children with 16 items. Parents rate 16 items with "yes" or "no." A cut-off of $\geq 3$ is considered as clinically relevant for depressive symptoms (Fuhrmann et al., 2014; Luby et al., 2004).

IQ was assessed by the Reynolds Intellectual Assessment Scales and Screening (RIAS) with four subtests (Hagmann-von Arx \& Grob, 2014). The IQ values of patients who had already undergone an intelligence test within outpatient diagnostic/treatment were transferred.

Parental stress was measured by the German version of the Parental Stress Index (PSI) (Eltern-Belastungs-Inventar, EBI; Tröster, 2011). The PSI differentiates between stress induced by child-specific factors (distractibility/hyperactivity, adaptability, demandingness, mood, acceptability, reinforces parent) and stress induced by parental factors (depression, competence, parental attachment, isolation, spouse/parenting partner relationship, health, role restriction). These two domains (child and parent domain) can be calculated separately and can be also combined to become the total stress index. The index and domain scores are outlined as $T$-values and stanines, with a $T$-value $\geq 60$ and a stanine $\geq 7$ regarded as clinically relevant.

\section{Clinical Interview}

The SIVA (Strukturiertes Interview für das Vorschulalter 0-6; Structured Interview for Preschool Age (0-6 years) (In-Albon et al., 2020; Bolten, 2020) is a structured interview for parents to assess mental disorders in children aged 0 to 6;11 years. It consists of a basic module and three different age-adjusted modules. The SIVA basic module includes the assessment of developmental and family history, psychosocial risks, developmental milestones, and chronic diseases, e.g., asthma or diabetes. The main modules include items for mental and developmental disorders and enable diagnostic evaluation of mental disorders according to ICD-10 (WHO, 1992), DSM-5 (APA, 2013), and Diagnostic Classification of Mental Health and Developmental Disorders of Infancy and Early Childhood (DC:0-5) (ZERO TO THREE, 2016). For the present study, children were diagnosed according to ICD-10. Two medical students in their final study phase and with prior experience with psychiatric patients received equal training for the SIVA interview from an expert in the field of child and adolescent psychiatry. The trained interviewers conducted equal amounts of the interviews across both groups and documented all interview information on standardized forms. In any case of hesitancy, the interviewers consulted their SIVA trainer for diagnostic validation.

\section{Statistics}

IBM SPSS Statistics 23 (IBM Corp. Released 2015. IBM SPSS Statistics for Windows, Version 23.0. Armonk, NY: IBM Corp.) was used for statistical analyses. To analyze differences in frequencies regarding incontinence symptoms, mental diagnoses, and clinically relevant questionnaire data between children with incontinence vs. children of the control group and between children with only UI vs. children with FGID, we performed $\chi^{2}$-tests or Fisher's exact tests, depending on sample sizes, respectively. $T$-tests or Mann-Whitney U-tests for independent samples were calculated to analyze significant differences regarding age, IQ, psychological symptoms, and parental stress levels between the aforementioned groups, depending on actual sample sizes, respectively. For analyzing main effects and interaction effects regarding incontinence and mental disorders on parental stress between parents of patients and TD children, we calculated analysis of variances (ANOVA). The significance level was set at a two-tailed alpha-error level of $p<.05$.

\section{Results}

\section{Psychiatric Comorbidity}

In total, 15 (39.5\%) children of the patient group and 13 $(31.0 \%)$ children of the control group had at least one (comorbid) mental disorder according to the SIVA interview based on ICD-10 criteria. Frequency of mental comorbidity did not differ between TD children and children with incontinence $\left(\chi^{2}(1)=.064, p=.425\right)$ and was independent of the incontinence subtype, as $4(40.0 \%)$ of the children with only UI and $11(39.3 \%)$ of the children with FGID were affected, Fisher's exact test $(p=1.000)$. Nonorganic insomnia, sleep terrors, ADHD, ODD, anxiety disorders, elective mutism, reactive attachment disorder, and tic disorders were present in both groups (Table 2); the differences between patients and controls were not significant, nor were the differences between children with only UI and children with FGID.

\section{Psychological Symptoms and Parental Stress}

\section{Children with Incontinence vs. TD Children}

Children with incontinence had higher internalizing, externalizing, and total CBCL problem scores than TD children (Table 3). Thus, children with incontinence exhibited more frequently clinically relevant CBCL T-values $\left(>90^{\text {th }}\right.$ 
Table 2. ICD-10 mental disorders in children with incontinence and TD children

\begin{tabular}{|c|c|c|c|c|}
\hline & \multicolumn{2}{|c|}{ TD children } & \multicolumn{2}{|c|}{$\begin{array}{l}\text { Children with } \\
\text { incontinence }\end{array}$} \\
\hline & $n$ & (\%) & $n$ & (\%) \\
\hline $\begin{array}{l}\text { At least one (comorbid) dis- } \\
\text { order }\end{array}$ & 13 & $(31.0)$ & 15 & (39.5) \\
\hline $\begin{array}{l}\text { F51.0 Nonorganic } \\
\text { insomnia }\end{array}$ & 3 & (7.1) & 3 & (7.9) \\
\hline F51.4 Sleep terrors & 1 & (2.4) & 0 & $(0.0)$ \\
\hline F90.0 ADHD & 1 & (2.4) & 4 & (10.5) \\
\hline $\begin{array}{l}\text { F90.1 Hyperkinetic } \\
\text { conduct disorder }\end{array}$ & 2 & $(4.8)$ & 2 & (5.3) \\
\hline F91 Conduct disorders & 1 & (2.4) & 1 & (2.6) \\
\hline $\begin{array}{l}\text { F91.3 Oppositional } \\
\text { defiant disorder }\end{array}$ & 4 & (9.5) & 4 & (10.5) \\
\hline $\begin{array}{l}\text { F93.0 Separation } \\
\text { anxiety disorder }\end{array}$ & 1 & (2.4) & 1 & (2.6) \\
\hline F93.1 Phobic anxiety disorder & 3 & $(7.1)$ & 2 & (5.3) \\
\hline F94.0 Elective mutism & 1 & $(2.4)$ & 2 & (5.3) \\
\hline $\begin{array}{l}\text { F94.1 Reactive } \\
\text { attachment disorder }\end{array}$ & 2 & $(4.8)$ & 2 & (5.3) \\
\hline F95 Tic disorders & 0 & $(0.0)$ & 1 & (2.6) \\
\hline
\end{tabular}

Note: $N_{\text {TD children }}=42, N_{\text {children with incontinence }}=38$. Diagnoses of mental disorders based on ICD-10 criteria and assessed with the SIVA. Statistical analysis of frequency distribution revealed no significant effect for sex. TD = typically developing.

percentile) regarding externalizing problems (Table 4). TD children and children with incontinence differed neither regarding their depressive scores on the PFC (Table 3) nor in the rates of clinically relevant internalizing problems or PFC scores, respectively (Table 4). Parents of children with incontinence did not report higher $T$-values regarding the PSI parental domain (PSI-PD) or the PSI total score than parents of TD children but reported higher $T$-values regarding the PSI child domain (PSI-CD) than parents TD children (Table 3). Nonetheless, the rates of clinically relevant PSI scores did not differ between parents of patients and TD children (Table 4).

\section{Children with Incontinence: UI vs. FGID}

Comparisons within the incontinence group revealed that children with UI only and children with FGID did not differ in their CBCL T-values, PFC sum scores, or PSI-CD and PSI-PD T-values; also, they did not report different rates of clinically relevant scores on the aforementioned variables (see Table 3 and Table 4).

\section{Main Effects and Interaction of Incontinence and Mental Disorders on Parental Stress}

\section{Children with Incontinence vs. TD Children: PSI-CD}

Results of the ANOVA showed that the PSI-CD score was significantly higher if a (comorbid) mental disorder was present $\left(F(1 ; 76)=35.98, \eta^{2}=0.32, p<.001\right)$. There was neither a significant interaction effect between the occurrence of mental disorder and group, $\left(F(1 ; 76)=3.48, \eta^{2}=\right.$ $0.04 p=.066$ ) nor a significant main effect for group $\left(F(1 ; 76)=1.22, \eta^{2}=0.02, p=.273\right)$, suggesting that patients and TD children did not differ per se in their PSI-CD score. Separate $t$-tests revealed that parents of TD children $(t(40)$ $=5.98, p<.001$; Cohen's $d=2.00)$ and parents of children with incontinence $(t(36)=2.73, p<.001$; Cohen's $d=0.91)$ had higher PSI-CD scores when their child had a (comorbid) mental disorder.

\section{Children with Incontinence vs. TD Children: PSI-PD}

The PSI-PD score was significantly higher if a (comorbid) mental disorder was present $\left(F(1 ; 76)=9.95, p=.002, \eta^{2}=\right.$ 0.11). There was also a significant interaction between the occurrence of mental disorder and incontinence, suggesting that parental stress in the control group was lower if the children had no mental disorder, though it was higher if the children had a mental disorder $(F(1 ; 76)=9.58, p=.003$, $\left.\eta^{2}=0.11\right)$. There was no main effect for incontinence, suggesting that parents of patients and parents of TD children did not differ per se in their PSI-PD score $(F(1 ; 76)<1, p=$ .624). Separate $t$-tests revealed that parents of TD children $(t(40)=4.88, p=.010$; Cohen's $d=1.63)$ but not parents of patients $(t(36)=04, p=.970$; Cohen's $d=0.01)$ had higher PSI-PD scores when their children had (comorbid) mental disorders (see Figure 1).

\section{Discussion}

We aimed to fill the gap of research on children's incontinence and parental stress by specifically focusing on the interaction effects of mental comorbidity and its impact on behavioral problems even at a young age. Our results clearly emphasized that children with incontinence are more affected by psychological symptoms and exhibit higher rates of clinically relevant externalizing problems than the TD children. Therefore, the high comorbidity of psychological symptoms that accompany incontinence problems is just as present as it is in older children (Equit, Klein et al., 2014; Equit, Hill et al., 2014; Kilincaslan et al., 2014; Niemczyk et al., 2014; Niemczyk et al., 2015; von Gontard, Moritz et al., 2011) (e.g., 2-4, 8-10). Nonethe- 
Table 3. Questionnaire data and mean differences on indices for children's psychological symptoms for TD children and children with incontinence

\begin{tabular}{|c|c|c|c|c|c|c|c|c|c|c|c|c|c|c|c|c|}
\hline & \multicolumn{3}{|c|}{ TD children } & \multicolumn{13}{|c|}{ Children with incontinence } \\
\hline & & & & & & & & & UI & & & FGI & & & & \\
\hline & $n$ & Mean & $(S D)$ & $n$ & Mean & $(S D)$ & $t$ & $p$ & $n$ & Mean & $(S D)$ & $n$ & Mean & $(S D)$ & $t$ & $p$ \\
\hline CBCL Int. & 42 & 44.76 & $(10.51)$ & 36 & 52.11 & $(9.36)$ & 3.24 & $.002^{\star \star}$ & 9 & 51.44 & $(10.75)$ & 27 & 52.33 & $(9.07)$ & -0.24 & .089 \\
\hline CBCL Ext. & 42 & 44.33 & $(11.70)$ & 36 & 52.34 & $(12.50)$ & 2.94 & $.004 * \star$ & 9 & 51.89 & $(15.42)$ & 27 & 52.56 & $(11.70)$ & -0.14 & .892 \\
\hline CBCL Tot. & 42 & 43.00 & $(10.92)$ & 36 & 52.58 & $(11.13)$ & 3.83 & $<.001 * \star \star$ & 9 & 53.56 & $(15.15)$ & 27 & 52.26 & (9.78) & 0.24 & .815 \\
\hline PSI-CD & 42 & 52.05 & $(10.42)$ & 38 & 56.26 & (9.64) & 1.87 & $.032 *$ & 10 & 53.30 & (10.89) & 28 & 57.32 & (9.12) & -1.04 & .315 \\
\hline PSI-PD & 42 & 51.00 & (9.65) & 38 & 52.39 & $(9.26)$ & 0.66 & .512 & 10 & 48.60 & (9.55) & 28 & 53.75 & (8.94) & -1.54 & .133 \\
\hline PSI Total & 42 & 51.26 & (10.85) & 38 & 54.13 & (9.89) & 1.23 & .222 & 10 & 50.70 & (10.11) & 28 & 55.36 & (9.70) & -1.29 & .205 \\
\hline PFC & 40 & 0.70 & $(1.29)$ & 38 & 1.21 & $(1.70)$ & 1.49 & .140 & 10 & 1.30 & (2.06) & 28 & 1.18 & $(1.58)$ & 0.19 & .849 \\
\hline
\end{tabular}

Note: $\mathrm{CBCL}=$ Child Behavior Checklist; Int. = Internalizing Symptom Score; Ext. = Externalizing Symptom Score; Tot = Totally Symptom Score; FGID = functional gastro-intestinal disorders; PSI = Parental Stress Index; PSI-CD = PSI Child domain; PSI-PD = PSI parent domain; PSI Total = PSI Total Score; PFC = Preschool Feeling Checklist. TD = typically developing; UI = Urinary incontinence; higher values indicate higher amounts of behavioral problems or stress, respectively. ${ }^{* *}$ Significant at $p \leq .001, * \star$ Significant at $p \leq .05, *$ Significant at one-tailed $p \leq .05$.

Table 4. Frequency of clinically relevant psychological symptoms and parental stress levels

\begin{tabular}{|c|c|c|c|c|c|c|c|c|c|c|}
\hline & \multicolumn{2}{|c|}{ TD children } & \multicolumn{8}{|c|}{ Children with incontinence } \\
\hline & & & & & & UI & & FGID & & \\
\hline & $n$ & (\%) & $n$ & (\%) & $p$ & $n$ & (\%) & $n$ & (\%) & $p$ \\
\hline CBCL Int. & 2 & $(4.8)$ & 4 & $(11.1)$ & .406 & 2 & $(22.2)$ & 2 & $(7.4)$ & .255 \\
\hline CBCL Ext. & 1 & $(2.4)$ & 8 & $(22.4)$ & $.010 *$ & 3 & (33.3) & 5 & $(18.5)$ & .384 \\
\hline CBCL Tot. & 1 & $(2.4)$ & 5 & (13.9) & .090 & 2 & $(22.2)$ & 3 & $(11.1)$ & .581 \\
\hline PSI Total & 9 & $(21.4)$ & 12 & $(31.6)$ & .322 & 2 & $(20.0)$ & 10 & $(35.7)$ & .453 \\
\hline PFC & 5 & $(12.5)$ & 8 & $(21.1)$ & .372 & 2 & $(20.0)$ & 6 & $(21.4)$ & 1.000 \\
\hline
\end{tabular}

Note: FGID = functional gastro-intestinal disorders; $\mathrm{UI}=$ Urinary incontinence; $\mathrm{CBCL}=$ Child Behavior Checklist; $\mathrm{CBCL}$ Int. = Internalizing Symptom Score; CBCL Ext. = CBCL Externalizing Symptom Score; CBCL Tot = CBCL Totally Symptom Score; $p$-values were calculated by Fisher's exact test; scores were considered as clinically relevant if they exceeded a $T$-value $>63$ (CBCL), a $T$-value $\geq 60$ (PSI), or exceeded a sum score $\geq 3$ (PFC). *Significant at $p \geq .05$.

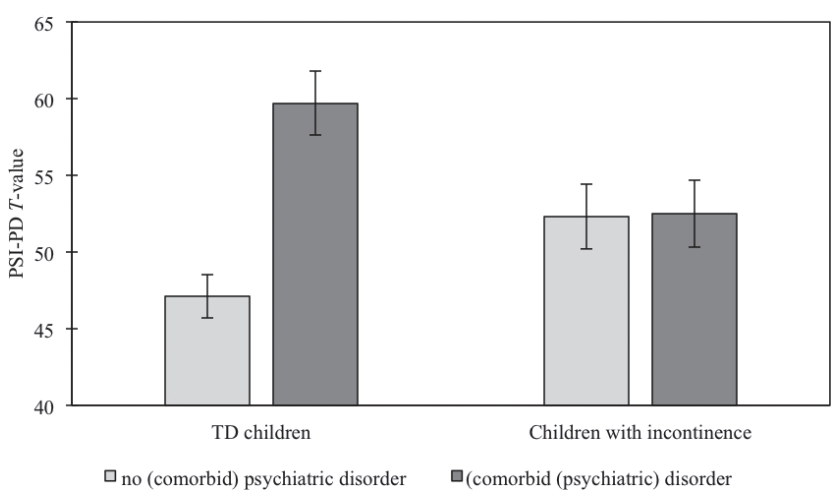

Figure 1. Interaction between incontinence and comorbid mental disorders on Parental Stress Index parental domain (PSI-PD). less, frequency of an existing mental disorder did not differ between both groups.

In contrast to other studies (von Gontard, Baeyens et al., 2011) children with FGID did not have higher rates of psychological problems than those with UI only. The difference might be due to the small and unbalanced subsample sizes (UI $n=10$ vs. FGID $n=28$ ), but it could also be explained by the young age of the children (mean age of 6.0 years in the UI and 5.3 years in the FGID group). One could speculate that the distress could be comparable for children with UI and FGID at a young age but could differ with increasing age or after school entrance. For example, the average quality of life in children with FI is much lower 
than in TD older children (Equit et al., 2014), especially regarding social and school functioning (Cushing et al., 2016). Nonetheless, FI is associated with higher rates of mental comorbidities (Niemczyk et al., 2015), with rather longer treatment duration and more persistent symptoms than UI in children with a mean age of 8.2 years (Borch et al., 2013).

Parents of young incontinent children did not experience higher stress as measured by parental stress factors compared to parents of TD children. The PSI-PD consists of constructs, e.g., the extent to which they feel comfortable and are capable in the parenting role (competence), their sense of closeness with the child (attachment), or their own affective state (depression). As there was no significant difference on PSI-PD across both groups, incontinence does not seem to impact parental stress levels based on adults' characteristics. Nonetheless, children's characteristics, e.g., parent's experience of the child as being demanding (demandingness) or the extent to which the child meets the expectations of the parent (acceptability) (PSI$\mathrm{CD}$ ), are perceived as more difficult compared to TD children. One might speculate that parents of young children attribute incontinence as a rather child-owned deficiency than as a parental susceptible state.

When comparing parental stress levels (both PSI-PD and PSI-CD) between children with only UI and children with FGID, there was no difference regarding parental stress, suggesting that parents differ neither in their experienced parental competence nor in their perceptions of their children's demandingness or characteristics.

Higher levels of parental stress are associated with lower rates of parenting satisfaction, parental control attribution, children's disruptive behavior, and quality of parentchild interaction (Begle et al., 2010). As the relationship between parental stress and the development of children's coping behavior is found to be bidirectional (Cappa et al., 2011), their psychological symptoms easily influence parental stress and vice versa. Therefore, the parenting style and perception of parenting competence might buffer children's demands to a certain degree, without interfering with family functioning or impeding parent-child interaction. If the child's demands constantly exceed their parents' ability to compensate their needs, e.g., when incontinence symptoms increase or additional psychological symptoms occur, this may lead to higher parental stress levels. Conceivably, incontinence might only influence parental emotional stability when parents experience stress that exceeds their competence. Otherwise, parents might tolerate incontinence at younger age to an initial greater extent as it might be seen as just an unfavorable norm variant in tidiness education.

More generally, parents of children with incontinence could experience very specific stressful situations because of the incontinence problems, which cannot be assessed by the PSI. For example, critical parenting situations or feelings of a lack of parenting competence could possibly affect very circumscribed parent-child interactions. In particular, those parents might experience highly specific stress regarding the toilet training of their children, but simultaneously interpret their general parenting skills as well established. In future studies, general and toilet-specific types of stress should be differentiated.

In contrast to our hypotheses, children with incontinence and controls did not differ regarding prevalence of co-occurring mental disorders. This might be due to sampling biases (discussed below) as well as the following specific aspects of the diagnostic methodology of this study: In addition to other standardized interviews, the targeted problems of the SIVA also capture diagnostic criteria of the DC:0-5, which enable a more differentiated focus on psychiatric symptoms in young children. The in-depth questions might have encouraged parents to report habitually overlooked symptoms and might have facilitated the psychiatric evaluation on the diagnostician's side because of the detailed information content. Since a validated interview was performed by equally skilled and supervised interviewers, the possibility that the finding of high rates of mental disorders in the study population results from the applied methodology seems rather low.

Because participants of the control group were indirectly recruited, study participation a priori required more proactiveness compared to the patient group, where participants were directly recruited. It remains speculative whether parents showing interest in the study had already been considering a psychiatric evaluation of their child, potentially even regarding the study's topic of incontinence. To prevent a sampling bias driven by simultaneous medical (psychiatric) consultation in the local clinic center, participants of the control group were recruited only from the general population. The eligibility criteria included an IQ $>70$ and absence of any incontinence diagnosis, but previous treatments or diagnostic evaluations were not systematically assessed. Therefore, we cannot definitively rule out that some parents might have sought a psychiatric consultation outside of regular healthcare with presumably long waiting times. Additionally, stress was higher if a (comorbid) mental disorder was present, but only for parents of the control group: Within the group of children with incontinence, parental stress levels did not differ regarding their child's comorbid mental disorder. Thus, it can be concluded that the significant main effect as well as the significant interaction effect of the $2 \times 2$ ANOVA (PSI-PD) solely based on the difference within the control group. Thereby, it can be said that, unless there was any significant effect, the parental stress on a group level for both patient and TD group remained within the normal range. 
Selection biases may explain this difference, as highly stressed parents with demanding children were less willing to participate in a study with no primary therapeutic benefit. Therefore, parents seeking medical/psychiatric intervention for their children's incontinence problems are more likely to participate in a study if their stress levels are low. Vice versa, stressed parents could be more likely to refuse to participate in any additional examinations beyond the medical appointment. Otherwise, it could be hypothesized that parents of controls who experience higher stress levels are more likely to participate in a study as a low-threshold therapeutic intervention if they themselves experience higher stress levels.

The comparable parental stress levels could also be due to the unusually high prevalence of mental disorders in the control group. Transcultural studies indicate the prevalence of childhood mental disorders at $13.4 \%$ according to ICD and DSM, whereas in this control group the prevalence was $29.5 \%$ (Polanczyk et al., 2015). Along with elevated stress levels, the selection biases within the control group might serve as a cofounding factor with higher prevalence of mental disorders. Even though the high prevalence of mental disorders within children of the control group might be unexpected, this leads to a higher comparability of both groups and reveals a better interpretability of effects on parental stress. Additionally, the prevalence of $11.4 \%$ of incontinence symptoms matches the characteristics of the general population, where NE and DUI symptoms occur with a prevalence of almost $10 \%$ among 7-year-olds (von Gontard \& Lehmkuhl, 2009).

In both groups, the mean IQ lies clearly above the populations' mean of 100. This is surprising, as previous studies usually report IQ scores tending to disperse more on the left side of the normal distribution regarding the patient but not the TD group, which might be due to the small sample size. One might also assume a selection bias, in that families of children with general higher functionality (of both groups) were more likely to participate in our study. However, we can state that our patient and control group differ for the obvious incontinence and associated FGID but are highly comparable regarding all other study characteristics. Therefore, our results are more likely to be explained by systematic effects of incontinence/FGID than by the effects of other confounding variables.

\section{Strengths and Limitations}

If we take mutual associations into account, this study shows its strength in putting a concurrent light on young children and their parents. Another strength is the use of standardized instruments to assess incontinence, mental disorders, and parental stress. The SIVA is a validated and highly structured clinical interview, providing reliable diagnoses specifically in this young age group. Nevertheless, our study is not free from limitations. The rather small sample size $\left(N=80, n_{\text {patients }}=42, n_{\mathrm{TD}}=38\right)$ might restrict generalizability of our findings. As discussed above, the sample size may account for higher rates of mental disorders, higher IQ, or lower parental stress levels. Besides the subsample sizes, within our patient group we subsumed different types of incontinence, that is, FGID as well as TRS. While these disorder categories share a phenomenological background (e.g., difficulties in tidiness education) and are usually accompanied by one another, there are substantial etiological (e.g., neurobiological etiology of $\mathrm{NE}$ ), diagnostic (e.g., different age criteria), and behavioral (e.g., varying comorbidity rates) differences that lead to heterogeneity and might narrow the generalizability of our results.

In our cross-sectional design, we could not include the data of all possible confounding factors. Therefore, the quality of parent-child interaction might have had a greater influence on parental stress and children's psychological symptoms than incontinence symptoms itself. Within a longitudinal design, the stability and quality of interaction styles to compare influences before and after the onset of incontinence symptoms could be assessed in a more detailed way.

Another limitation is that parents' psychopathology and the history of mental disorders in parents were not assessed. The presence of maternal psychopathology might have influenced the perceived behavioral difficulties of their children. For example, mothers with perinatal mental disorder tend to perceive their children as more difficult compared to mothers who did not develop any mental disorders after childbirth (Polanczyk et al., 2015). Also, mental disorders are closely interrelated with parental stress and both increase an infant's risk of being perceived as difficult (Mäntymaa et al., 2006).

\section{Conclusions}

Psychological symptoms and difficult behavioral and psychological characteristics are more common in children with incontinence, irrespective of having UI or FI. Children with incontinence are perceived to be more demanding by their parents, as child domain specific stress scores tend to be higher. However, incontinence in younger children does not seem to influence parental stress in general. Parents appear to cope well with associated emotional and behavioral difficulties in their young children with incontinence. Despite moderate stress levels that we assessed in this study, 
we want to emphasize that incontinence symptoms, UI and FI are highly prevalent in young children. $11.4 \%$ of children of the initial control group showed UI symptoms, but never underwent an incontinence specific psychiatric/medical treatment or assessment. Particularly within the control group, the presence of mental disorders significantly intensifies parental stress levels. Given the high temporal stability of unattended incontinence symptoms and psychological symptoms, it is necessary to evaluate their clinical relevance, as well as parental stress especially at young age to initiate an appropriate treatment and to prevent negative consequences at an early stage. Future studies should shift their focus more on long-term studies and simultaneous assessing parents' psychopathology and the quality of parentchild interaction/relationship. These could identify risk and protective factors as well as the influences between children's incontinence symptoms and parental stress.

\section{Literature}

American Psychiatric Association. (2013). Diagnostic and statistical manual of mental disorders (5th ed.). APA. https://doi. org/10.1176/appi.books.9780890425596

Austin, P.F., Bauer, S. B., Bower, W., Chase, J., Franco, I., Hoebeke, P., Rittig, S., Vande Walle, J., von Gontard, A., Wright, A., Yang S. S., \& Neveus, T. (2016). The standardization of terminology of lower urinary tract function in children and adolescents: Update report from the standardization committee of the International Children's Continence Society. Neurourology and Urodynamics, 35(4), 471-481.

Begle, A.M., Dumas, J.E., \& Hanson, R. F. (2010). Predicting child abuse potential: An empirical investigation of two theoretical frameworks. Journal of Clinical Child \& Adolescent Psychology, 39(2), 208-219.

Bolten, M. (2020). Das Strukturierte Interview für das Vorschulalter (SIVA: 0-6). Kindheit und Entwicklung, 29(4), 209-220.

In-Albon, T., Equit, M., von Gontard, A., Schwarz, D., Müller, J. M., \& Bolten, M. (2020). Das Strukturierte Interview für das Vorschulalter (SIVA:0-6). Kindheit und Entwicklung, 29, 209-220. https:// doi.org/10.1026/0942-5403/a000319

Borch, L., Hagstroem, S., Bower, W. F., Siggaard Rittig, C., \& Rittig, S. (2013). Bladder and bowel dysfunction and the resolution of urinary incontinence with successful management of bowel symptoms in children. Acta Paediatrica, 102(5), e215-e220.

Cappa, K.A., Begle, A. M., Conger, J.C., Dumas, J.E., \& Conger, A.J. (2011). Bidirectional relationships between parenting stress and child coping competence: Findings from the PACE Study. Journal of Child and Family Studies, 20(3), 334-342.

Christophersen, E.R., \& Edwards, K.J. (1992). Treatment of elimination disorders: State of the art 1991. Applied and Preventive Psychology, 1(1), 15-22. https://doi.org/10.1016/S0962-1849 (05)80131-3

Cushing, C.C., Martinez-Leo, B., Bischoff, A., Hall, J., Helmrath, M., Dickie, B.H., Levitt, M.A., Peña, A., Zeller, M.H., \& Frischer, J.S. (2016). Health-related quality of life and parental stress in children with fecal incontinence: A normative comparison. Journal of Pediatric Gastroenterology and Nutrition, 63(6), 633636. https://doi.org/10.1097/mpg.0000000000001201
De Bruyne, E., Van Hoecke, E., Van Gompel, K., Verbeken, S., Baeyens, D., Hoebeke, P., \& Walle, J.V. (2009). Problem behavior, parental stress and enuresis. The Journal of Urology, 182(4), 2015-2021.

Döpfner, M., Plück, J., \& Kinnen, C. (2014). Manual deutsche Schulalter-Formen der Child Behavior Checklist von Thomas M. Achenbach. Elternfragebogen über das Verhalten von Kindern und Jugendlichen (CBCL/6-18R), Lehrerfragebogen über das Verhalten von Kindern und Jugendlichen (TRF/6-18R), Fragebogen für Jugendliche (YSR/11-18R). Hogrefe.

Equit, M., Hill, J., Hübner, A., \& Von Gontard, A. (2014). Health-related quality of life and treatment effects on children with functional incontinence, and their parents. Journal of Pediatric Urology, 10(5), 922-928.

Equit, M., Klein, A.-M., Braun-Bither, K., Gräber, S., \& von Gontard, A. (2014). Elimination disorders and anxious-depressed symptoms in preschool children: A population-based study. European Child \& Adolescent Psychiatry, 23(6), 417-423.

Fuhrmann, P., Equit, M., Schmidt, K., von Gontard, A., \& Psychiatry, A. (2014). Prevalence of depressive symptoms and associated developmental disorders in preschool children: A population-based study. European Child \& Adolescent Psychiatry, 23(4), 219-224.

Hagmann-von Arx, P., \& Grob, A. (2014). RIAS-Reynolds intellectual assessment scales and screening: deutschsprachige Adaptation der Reynolds Intellectual Assessment Scales (RIAS) \& des Reynolds Intellectual Screening Test (RIST) von Cecil R. Reynolds und Randy W. Kamphaus: Manual. Hans Huber.

Hyams, J.S., Di Lorenzo, C., Saps, M., Shulman, R.J., Staiano, A., \& van Tilburg, M. (2016). Childhood functional gastrointestinal disorders: Child/adolescent. Gastroenterology, 150(6), 14561468. e1452.

Kaugars, A.S., Silverman, A., Kinservik, M., Heinze, S., Reinemann, L., Sander, M., Schneider, B., \& Sood, M. (2010). Families' perspectives on the effect of constipation and fecal incontinence on quality of life. Journal of Pediatric Gastroenterology and Nutrition, 51(6), 747-752.

Kilincaslan, H., Abali, O., Demirkaya, S. K., \& Bilici, M. (2014). Clinical, psychological and maternal characteristics in early functional constipation. Pediatrics International, 56(4), 588-593.

Luby, J.L., Heffelfinger, A., Koenig-McNaught, A.L., Brown, K., \& Spitznagel, E. (2004). The preschool feelings checklist: A brief and sensitive screening measure for depression in young children. Journal of the American Academy of Child \& Adolescent Psychiatry, 43(6), 708-717.

Mäntymaa, M., Puura, K., Luoma, I., Salmelin, R. K., \& Tamminen, T. (2006). Mother's early perception of her infant's difficult temperament, parenting stress and early mother-infant interaction. Nordic Journal of Psychiatry, 60(5), 379-386.

Niemczyk, J., Equit, M., Braun-Bither, K., Klein, A.-M., \& von Gontard, A. (2015). Prevalence of incontinence, attention deficit/ hyperactivity disorder and oppositional defiant disorder in preschool children. European Child \& Adolescent Psychiatry, 24(7), 837-843.

Niemczyk, J., Equit, M., El Khatib, D., \& von Gontard, A. (2014). Toilet refusal syndrome in preschool children: Do different subtypes exist? Journal of Pediatric Gastroenterology and Nutrition, 58(3), 303-306.

Polanczyk, G.V., Salum, G.A., Sugaya, L.S., Caye, A., \& Rohde, L.A. (2015). Annual research review: A meta-analysis of the worldwide prevalence of mental disorders in children and adolescents. Journal of Child Psychology and Psychiatry, 56(3), 345-365. https://doi.org/ 10.1111/jcpp.12381

Schober, J.M., Lipman, R., Haltigan, J.D., \& Kuhn, P.J. (2004). The impact of monosymptomatic nocturnal enuresis on attachment parameters. Scandinavian Journal of Urology and Nephrology, 38(1), 47-52. 
Taubman, B. (1997). Toilet training and toileting refusal for stool only: A prospective study. Pediatrics, 99(1), 54-58.

Tröster, H. (2011). Eltern-Belastungs-Inventar (EBI); Deutsche Version des Parenting Stress Index (PSI) von RR Abidin. Hogrefe.

von Gontard, A. (2012). Enuresis. In J. M. Rey (Ed.), IACAPAP e-textbook of child and adolescent mental health. International Association for Child and Adolescent Psychiatry and Allied Profession.

von Gontard, A., Baeyens, D., Van Hoecke, E., Warzak, W.J., \& Bachmann, C. (2011). Psychological and psychiatric issues in urinary and fecal incontinence. The Journal of Urology, 185(4), $1432-1437$.

von Gontard, A., \& Lehmkuhl, G. (2009). Leitfaden Enuresis. Hogrefe.

von Gontard, A., Moritz, A., Thome-Granz, S., \& Freitag, C. (2011). Association of attention deficit and elimination disorders at school entry: A population based study. The Journal of Urology, 186(5), 2027-2032.

von Gontard, A., Niemczyk, J., Thomé-Granz, S., Nowack, J., Moritz, A.-M., \& Equit, M. (2015). Incontinence and parent-reported oppositional defiant disorder symptoms in young children: A population-based study. Pediatric Nephrology, 30(7), 1147-1155. https://doi.org/10.1007/s00467-014-3040-z

World Health Organization (WHO). (1992). The ICD-10 classification of mental and behavioural disorders: clinical descriptions and diagnostic guidelines (Vol. 1). Author.

Wolfe-Christensen, C., Manolis, A., Guy, W.C., Kovacevic, N., Zoubi, N., El-Baba, M., Kovacevic, L. G., \& Lakshmanan, Y. (2013). Bladder and bowel dysfunction: Evidence for multidisciplinary care. The Journal of Urology, 190(5), 1864-1868.

ZERO TO THREE. (2016). DC:0-5 ${ }^{\mathrm{TM}}$ : Diagnostic classification of mental health and developmental disorders of infancy and early childhood: Revised edition (DC:0-5). Author.

\section{Ethics Approval and Consent to Participate}

The study was approved by the local ethics committee and is in accordance with the ethical standards of the Declaration of Helsinki (2013). Informed consent was obtained from all individual participants included in the study.

\section{History}

Manuscript submitted: 02.09.2020

Accepted after revision: 16.03.2021

Published online: 07.05.2021

\section{Acknowledgments}

We are thankful to all patients and parents who contributed to this work.

\section{Funding}

Open access publication enabled by Saarland University

\section{Conflicts of interests}

The authors declare no conflicts of interest.

\section{Hannah K. Mattheus}

Kirrberger Straße, Gebäude 90.2

66421 Homburg

Germany

hannah.mattheus@uni-saarland.de 